\title{
Adaptive Backstepping Control Based on Floating Offshore High Temperature Superconductor Generator for Wind Turbines
}

\author{
Feng Yang, ${ }^{1}$ Sheng-shan Li, ${ }^{1}$ Lei Wang, ${ }^{2,3}$ Shan Zuo, ${ }^{3}$ and Qing-wang Song ${ }^{1}$ \\ ${ }^{1}$ School of Automation Engineering, University of Electronic Science and Technology of China, Chengdu 611731, China \\ ${ }^{2}$ School of Automation, Chongqing University, Chongqing 400044, China \\ ${ }^{3}$ School of Energy Science and Engineering, University of Electronic Science and Technology of China, Chengdu 611731, China \\ Correspondence should be addressed to Lei Wang; leiwang08@cqu.edu.cn
}

Received 18 February 2014; Revised 2 March 2014; Accepted 2 March 2014; Published 27 March 2014

Academic Editor: Peng Shi

Copyright (C) 2014 Feng Yang et al. This is an open access article distributed under the Creative Commons Attribution License, which permits unrestricted use, distribution, and reproduction in any medium, provided the original work is properly cited.

\begin{abstract}
With the rapid development of offshore wind power, the doubly fed induction generator and permanent magnet synchronous generator cannot meet the increasing request of power capacity. Therefore, superconducting generator should be used instead of the traditional motor, which can improve generator efficiency, reduce the weight of wind turbines, and increase system reliability. This paper mainly focuses on nonlinear control in the offshore wind power system which is consisted of a wind turbine and a high temperature superconductor generator. The proposed control approach is based on the adaptive backstepping method. Its main purpose is to regulate the rotor speed and generator voltage, therefore, achieving the maximum power point tracking (MPPT), improving the efficiency of a wind turbine, and then enhancing the system's stability and robustness under large disturbances. The control approach can ensure high precision of generator speed tracking, which is confirmed in both the theoretical analysis and numerical simulation.
\end{abstract}

\section{Introduction}

Because of the reduction of fossil fuels and increasingly serious environmental pollution, wind energy is worldwidely recognized as a cost-effective, environmental-friendly solution to the energy shortage [1]. Wind energy conversion is becoming the fastest-growing energy in the world of renewable energy, and this trend will be retained for a long period of time. There has been an estimated 35 megawatts of wind energy capacity achieved in only 2013, which is more than any other renewable energies. The global wind power installed capacity increased by $16.6 \%$, reaching 318 megawatts (MW) (see Figure 1). During the period from 2006 to 2013, annual growth rates of cumulative wind power capacity achieved an averaged $20 \%$. China, USA, Germany, Spain, and India accounted for $73 \%$ of global installed wind power capacity (see Figure 2) [2].

At present, most wind turbines are operated onshore, making huge noise, which results in a negative impact to people's life. The wind farms occupy a large area of land, so the onshore wind power technology is believed to be reliable. Due to transportation restrictions, the size of the onshore turbine is expected to be lower than the current size of 3 to $5 \mathrm{MW}$ [3]. A key part of the cost of offshore wind farm depends on the wind turbine foundation, maintenance, and grid connection. Therefore, the power ratings of 5-10 MW wind generator set placed at sea is desirable over the next 10 years [4].

Doubly fed induction generators (DFIGs) are mainly applied to the offshore wind turbine system nowadays [5, 6]. Their rated power is about $0.5-5 \mathrm{MW}$. The advantage of DFIG is to reduce costs of rated power electronic converters. However, the brush and slip ring of generator require regular maintenance. In addition, the reactive power needs electronic devices to provide compensation [7]. Currently, permanent magnetism synchronous generator (PMSG) is gradually applied to the wind energy system $[8,9]$. Their power rating is usually 2 to $6 \mathrm{MW}$. Clearly, PMSG provides possibility of reducing energy loss and the weight of the generator set. But the exist of permanent magnets, copper, and iron in generator make the magnetic flux density and power 


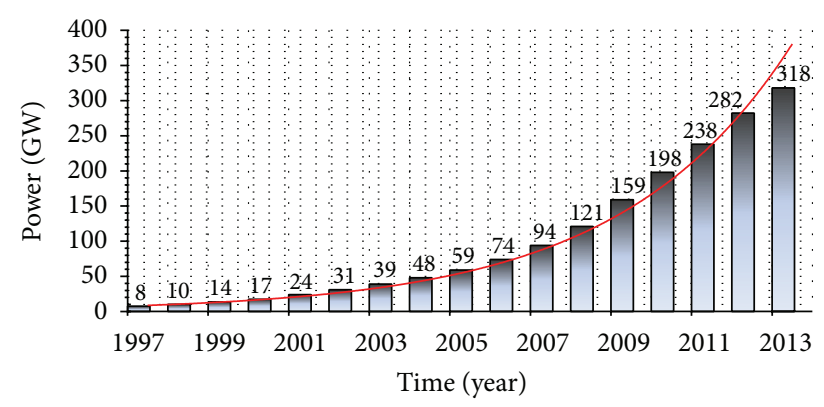

FIGURE 1: Wind power total capacity, 1997-2013.

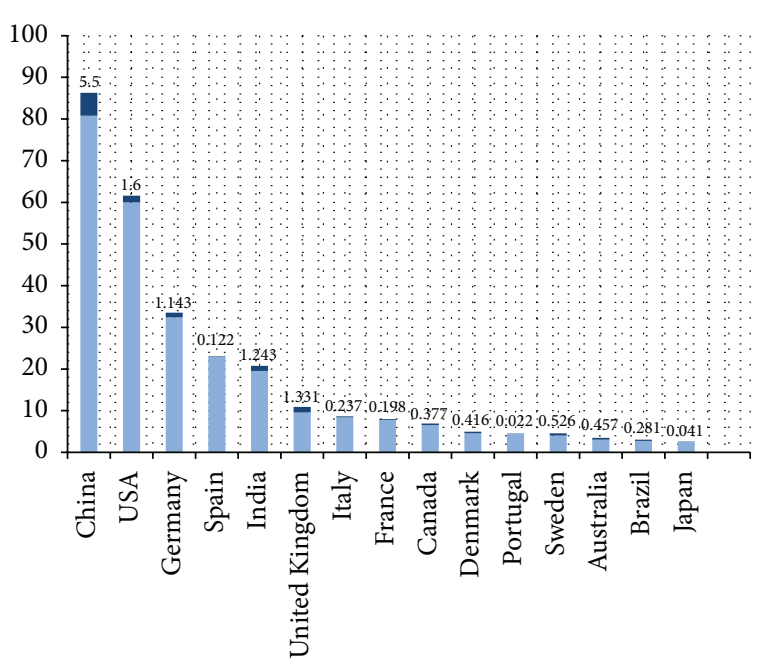

Installed capacity end 2012 (MW)

New installed capacity 2013 (MW)

FIgURE 2: Total installed capacity 2013 [MW].

density restricted [7]. Increasing the capacity of offshore wind turbines, improve reliability, reduce the weight of the generator, direct drive high temperature superconducting generators feasible than DFIG and PMSG. Removing the gear box has been considered to be the largest benefit by reducing the weight and volume of the wind turbine system [3].

Solutions to the problem of wind energy conversion system (WECS) development experience and grid connected wind turbines that require different control strategies. Therefore, a global optimization control method is necessary, in order to ensure energy conversion functionality and effectiveness of the system as a whole and to provide the quality of energy. Considering the poor atmospheric conditions and random nature of the primary energy, wind, these are not trivial tasks [10].

In this paper, a high temperature superconductor generator (HTSG) unit is embedded into the system to enhance the generated power quality. This is achieved by properly regulating the HTSG speed to maintain constant speed of the generator over a wide range of wind speed. It should be noted that DFIG has been widely used in high performance servo system where a rapid and accurate torque response is required because of their inherent advantages such as low inertia, high efficiency, and high power density compared to other turbines with the same capacity. The main task of the control system is to adjust the HTSG speed so as to improve power quality.

Reference [4] shows the possibility of a design of a direct-drive type $10 \mathrm{~kW}$ superconducting 8 synchronous generator, which is based on a $7.5 \mathrm{~km}$ high temperature superconducting coil and the generator may be shown up in a small wind turbine. Reference [11] shows the production and the specification of the magnetic field inside the generator. Finally, it is pointed out that superconducting generators for wind turbine have superconductors, vacuum, cryostat, and cooling challenges. The literature [12-14] describes different topologies of HTSG. But in the research of superconducting controlled application of wind turbines is less. This paper presented adaptive backstepping control strategy which is based on the nonlinear model of the wind turbines. The proposed controller has good stability and is able to achieve the MPPT of the wind turbines.

The rest of the paper is divided into the following several sections. Section 2 is dedicated to modeling framework of the considered turbine model and motor model. This model is used for the adaptive law design and stability analysis, as detailed in Section 3. Section 4 briefly presents the floating platform used in this paper. Section 5 contains simulation analysis. Section 6 introduces the conclusion.

\section{Wind Turbine Modeling}

2.1. Aerodynamic Modeling. A wind turbine extracts kinetic energy from the swept area of the blades. The power in the airflow is given by [15]:

$$
P_{a}=\frac{1}{2} \rho \pi R^{2} C_{p}(\lambda, \beta) v^{3},
$$

where $C_{p}$ is the power coefficient that depends on the tip speed ratio $\lambda, R$ is the rotor radius, $\rho$ is the air density, $\beta$ is the pitch angle, and $v$ is the wind speed.

One has

$$
\lambda=\frac{(R \omega)}{v},
$$

where $\omega$ is the rotor speed. The tip speed ratio $(\lambda)$ is key variable in the wind turbine control. It characterizes the power conversion efficiency and it is also used to define the acoustic noise levels.

From (1) and (2), we get the generator torque expressed as follows:

$$
P_{a}=K_{\omega} \omega^{3}=T_{a} \omega
$$




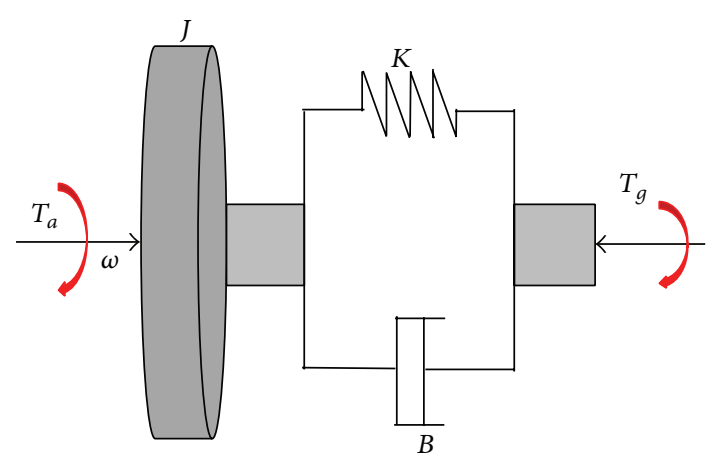

FIgURE 3: Wind turbine drive train.

where

$$
K_{\omega}=\frac{C_{p}(\lambda, \beta)}{2 \lambda^{3}} \rho \pi R^{5} .
$$

Direct drive HTSG wind tusrbine used the single-mass model representation, as shown in Figure 3.

A single mass for the wind turbine can be defined as

$$
\begin{gathered}
J \dot{\omega}=T_{a}-K \omega-T_{g}, \\
P_{a}=T_{a} \omega,
\end{gathered}
$$

where $J$ is the inertia, $T_{a}$ is the aerodynamic torque, $K$ is the damping, and $T_{g}$ is the generator torque.

\subsection{HTSG Modeling}

2.2.1. Superconductor Characteristic. Since the early 1960, high temperature superconducting winding has hopes to become the next generation of generator stator and rotor winding [16]. The high current density achieved by using superconductor in armature winding which makes it possible to create a small volume, light weight, and high power density machine. Rotor on the race track type high temperature superconducting magnetic field; it can significantly reduce motor mass and volume compared with the traditional motor. Second-generation (B-series/2G) superconductor is now available on the market, which can be used in the research and production of magnet and motor. It is rather difficult to apply B-series superconductor for magnets at liquid nitrogen temperature. The next generation of high temperature superconductivity electrical machinery B-series has characteristics of good current density and magnetic induction intensity. Particularly in the temperature range between $20 \mathrm{~K}$ and $50 \mathrm{~K}$, magnetic field effect on the critical current density is smaller [17].

The characteristics of superconductor mainly have the following several aspects. Firstly, zero resistance phenomenon. Superconductors under the low temperature environment, resistance suddenly disappeared. Secondly, Meissner effect, when the high temperature superconductivity at low temperatures, the resistance is zero, then the applied magnetic field so that the appropriate zero resistance disappears. Thirdly, critical magnetic field. Superconducting zero resistance phenomenon disappear with magnetic field intensity (see (6)). Fifthly, critical current, after that when current flows through the superconductor and reached a certain value, superconducting state is destroyed (see (7)):

$$
\begin{gathered}
H_{c}=H_{c}(0)\left[1-\left(\frac{T}{T_{c}}\right)^{2}\right], \\
I_{c}=I_{c}(0)\left[1-\left(\frac{T}{T_{c}}\right)^{2}\right],
\end{gathered}
$$

where $H_{c}(0)$ is $T=0 \mathrm{~K}$ superconductor critical magnetic field strength and $I_{c}(0)$ is $T=0 \mathrm{~K}$ superconductor critical current.

2.2.2. Generator Model. There are three main types of wind turbine generator; the first stage is DFIG. The system has two advantages: the generator slip ring is unnecessary that required regular maintenance and suitable converter capacity which can provide better low voltage through ability. DFIGbased wind turbines have some advantages such as the variable speed operation, active power, and reactive powerindependent control [18]. The main advantage of DFIG is providing constant voltage and frequency output for $\pm 30 \%$ speed variation in the traditional synchronous speed. The rotor speed reference generated by the MPPT control strategy was limited within a relatively small synchronous speed. Then, such system reduces converter cost and power loss compared with a synchronous generator based on the full rated converter system [19]. The failure rate of the speed increasing gearbox is higher, so its operation requires good alignment and mechanical lubricating system. In the past, the gearboxes are major problem affecting the reliability of the wind turbine, which also exists in the offshore wind turbines today.

The second stage is PMSG. Compared with gear growth mode, the direct-drive wind turbine system can simplify the drive train to increase energy output and reliability. PMSG system uses permanent magnet excitation and no additional power supply will need to provide excitation, which has high efficiency. However, due to the low-speed operation, directdrive PMSG may have deficiencies such as the large size, heavy weight, and high cost of generators [20].

The third stage is the HTSG. The increase of the volume and weight has inversely proportional relationship with the motor's rated speed decreases. The system as a whole benefits from the advantages of lower quality and size, and no gearbox. HTSG is able to solve the problem of DFIG and PMSG capacity (saturated magnetic field) and a superconducting generator with higher efficiency, lighter mass, and smaller volume. Through the use of high current density of a series of superconductors, produced by the high air gap magnetic flux density, will allow generator more compact [3]. The basic structure of HTSG can be seen in Figure 4. 


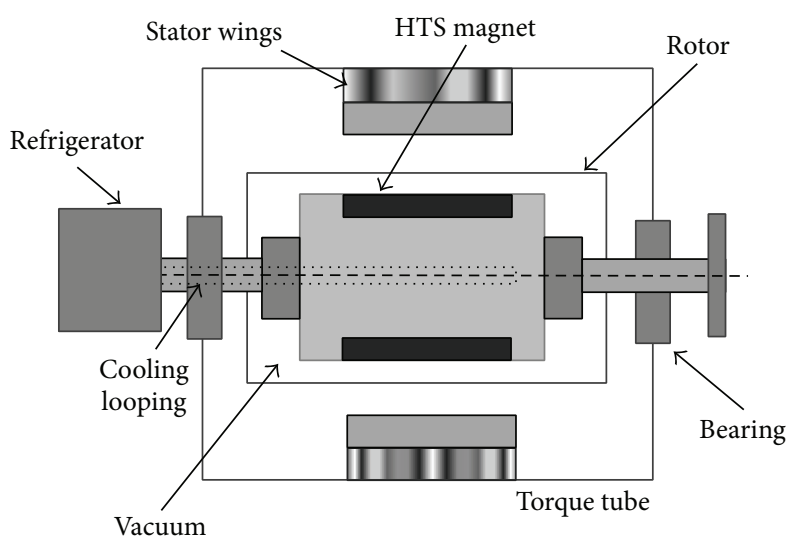

FIgURE 4: The basic structure of HTSG.

The electrical model of HTSG in the stator reference $(d-q)$ frame can be described as follows [21]:

$$
\begin{aligned}
& V_{d}=R_{s} i_{d}+\frac{L_{d} d i_{d}}{d t}-\omega_{r} \psi_{q}, \\
& V_{q}=R_{s} i_{q}+\frac{L_{q} d i_{q}}{d t}-\omega_{r} \psi_{d},
\end{aligned}
$$

where $V_{d}, V_{q}$ are $d$ and $q$ stator voltages; $L_{d}, L_{q}$ are $d$ and $q$ inductances; $\psi_{d}, \psi_{q}$ are $d$ and $q$ flux; $i_{d}, i_{q}$ are $d$ and $q$ current; $\omega_{r}$ is the rotor speed; and $R_{s}$ is the stator resistance.

One has

$$
\begin{gathered}
\psi_{d}=L_{d} i_{d}+\psi_{m} \\
\psi_{q}=L_{q} i_{q}
\end{gathered}
$$

where $\psi_{m}$ is the flux that is variation due to superconductor temperature and current.

The electromagnetic torque is obtained as

$$
T_{g}=p\left[\psi_{m} i_{q}+\left(L_{d}-L_{q}\right) i_{d} i_{q}\right]
$$

where $p$ is the number of pole pairs the HTSG.

From the electromagnetic torque equation, it can be seen that the torque control can be obtained by the regulation of $d$-axis and $q$-axis currents. Three currents produced by three-level inverters are used to obtain two currents through Clark and Park transformation. For HTSG with surface of superconducting windings, we have $L_{d}=L_{q}$, thus decouples the electromagnetic torque from the current component $i_{d}$. Our control objective is to ensure speed-tracking through designing the direct-axis and quadrature-axis stator voltages. In addition, the $d$-axis current is confined as zero.

\section{Controller Design}

3.1. Control Strategy. Generator torque is calculated by means of look-up table; the generator speed control area after filter is divided into four parts: $1,2,2.5$, and 3 [22]. The turbine control strategy in different control schemes depends on the operation area as shown in Figure 5. The generator torque

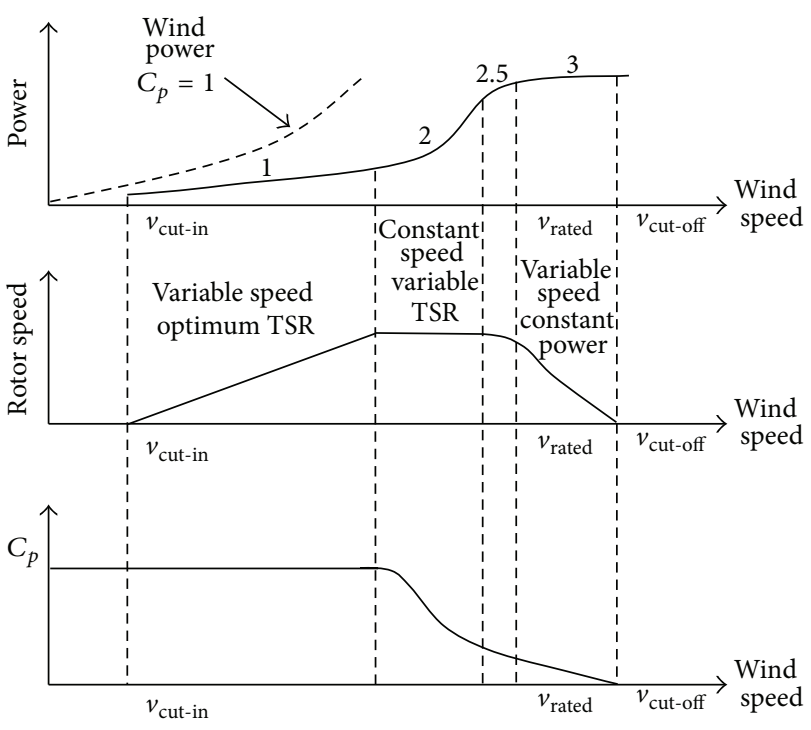

FIGURE 5: Wind turbine control region.

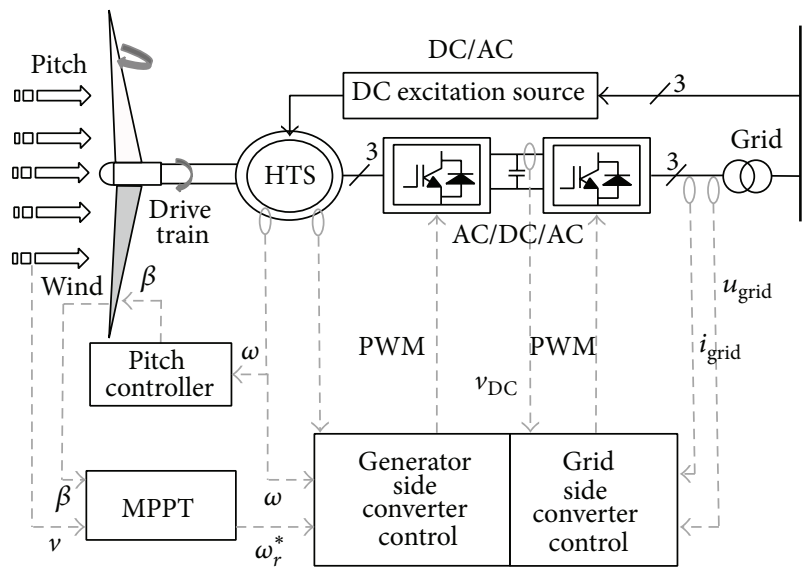

FIGURE 6: Configuration of a HTSG wind turbine.

is zero before cut-in wind speed in region 1 . In region 2 , input wind speed is lower than the rated wind speed. In order to realize the MPPT, pitch Angle in the optimal value and generator torque setting value is maximized. Here, the generator torque is proportional to the square of the filtered generator speed in order to maintain an optimal tipspeed ratio. In region 3, wind speed is above rated speed, generator torque remains unchanged, and blade-pitch keeps rated output and rotor speed by cutting excess air power. In order to realize the switch of the torque controller and pitch controller, region 2.5 is a linear transition between regions 2 and 3 [23].

In regions $2-3$, the demand torque is given by

$$
T(\omega)= \begin{cases}k \omega^{2} & \text { Region 2 } \\ T_{1}+\frac{T_{\text {rated }}-T_{1}}{\omega_{\text {rated }}-\omega_{1}} & \text { Region 2.5 } \\ T_{\text {rated }} & \text { Region 3. }\end{cases}
$$


3.2. Controller Design. A HTSG-based wind power generation system schematic diagram is shown in Figure 6. This figure describes the main components: the mechanical part (turbine, pitch drive) of the HTSG-based wind turbine system as well as the HTSG which can exchange power with the grid through the stator.

Superconducting windings have a constant magnetic field with external conditions (temperature, currents), from (5) to the flux of the expression:

$$
\psi_{m}=\alpha\left(H_{c}\right)+\beta\left(I_{c}\right)+\gamma\left(H_{c}, I_{c}\right),
$$

where $\alpha(\cdot), \beta(\cdot), \gamma(\cdot, \cdot)$ is the non-linear function on temperature and magnetic field strength, $\dot{\alpha}(\cdot)<\infty, \dot{\beta}(\cdot)<\infty$, $\dot{\gamma}(\cdot, \cdot)<\infty . \alpha(\cdot)$ is the magnetic field strength changes caused by changes in flux, $d$ is the current changes caused by changes in flux, and $x$ is the magnetic field strength and the current change caused by the change of the flux.

In order to facilitate the calculation, then from (8), (9), and (10) we have

$$
\begin{aligned}
& \frac{d i_{d}}{d t}=-\frac{i_{d} R_{s}}{L_{d}}+\frac{p \omega i_{q} L_{q}}{L_{d}}+\frac{V_{d}}{L_{d}}, \\
& \frac{d i_{q}}{d t}=-\frac{p \omega\left(L_{d} i_{d}+\psi_{m}\right)}{L_{q}}-\frac{i_{q} R_{s}}{L_{q}}+\frac{V_{q}}{L_{q}} .
\end{aligned}
$$

Equation (13) can be written as

$$
\begin{aligned}
& \dot{x}_{3}=-a_{1} x_{3}+a_{2} \omega x_{2}+a_{3} V_{d}, \\
& \dot{x}_{2}=-b_{1} \omega x_{3}-b_{2} \omega \psi_{m}-b_{3} x_{2}+b_{4} V_{q}, \\
& \dot{x}_{1}=\frac{1}{J}\left(T_{a}-K x_{1}-p\left[\psi_{m} x_{2}+b_{5} x_{2} x_{3}\right]\right),
\end{aligned}
$$

where $x_{1}=\omega, x_{2}=i_{q}, x_{3}=x_{2}, a_{1}=R_{s} / L_{d}, a_{2}=p L_{q} / L_{d}$, $a_{3}=1 / L_{d}, b_{1}=p L_{q} / L_{q}, b_{2}=p / L_{q}, b_{3}=R_{s} / L_{q}, b_{4}=$ $1 / L_{q}$, and $b_{5}=L_{d}-L_{q}$. Adaptive backstepping controller is designed as follows.

Step 1. The error variable is defined as

$$
\begin{aligned}
& z_{1}=x_{1}-x_{1}^{*}, \\
& z_{2}=x_{2}-\alpha_{1}, \\
& z_{3}=x_{3}-\alpha_{2},
\end{aligned}
$$

where $x_{2}$ and $x_{3}$ are virtual control variable, $\alpha_{1}$ and $\alpha_{2}$ are stable function of the system, $x_{1}$ is the practical position signal, and $x_{1}^{*}$ is the ideal position signal.

To make the subsystems is stable, select the Lyapunov function as

$$
\begin{gathered}
V_{1}=\frac{z_{1}^{2}}{2}, \\
\dot{V}_{1}=z_{1} \dot{z}_{1} .
\end{gathered}
$$

From (15), (16), we have

$$
\begin{aligned}
\dot{z}_{1}= & \dot{x}_{1}-\dot{x}_{1}^{*} \\
= & -\frac{K}{J} x_{1}-\frac{p \psi_{m}}{J} x_{2}-\frac{p b_{5}}{J} x_{2} x_{3}+\frac{T_{a}}{J}-\dot{x}_{1}^{*} \\
= & -\frac{K}{J}\left(z_{1}+x_{1}^{*}\right)-\frac{p \psi_{m}}{J}\left(z_{2}+\alpha_{1}\right)-\frac{p b_{5}}{J} x_{2}\left(z_{3}+\alpha_{2}\right) \\
& +\frac{T_{a}}{J}-\dot{x}_{1}^{*} .
\end{aligned}
$$

From (18), (19), when $z_{1} \neq 0 z_{2}=0 z_{3}=0$, (18) can be written as

$$
\dot{V}_{1}=z_{1}\left[-\frac{K}{J}\left(z_{1}+x_{1}^{*}\right)-\frac{p \psi_{m}}{J} \alpha_{1}-\frac{p b_{5}}{J} x_{2} \alpha_{2}+\frac{T_{a}}{J}-\dot{x}_{1}^{*}\right] \text {. }
$$

Select the stable function as

$$
\begin{aligned}
& \alpha_{1}=\frac{J}{p \psi_{m}}\left[c_{1} z_{1}-\frac{K}{J}\left(z_{1}+x_{1}^{*}\right)+\frac{T_{a}}{J}-\dot{x}_{1}^{*}\right], \\
& \alpha_{2}=0
\end{aligned}
$$

where $c_{1}>0$.

Then

$$
\dot{V}_{1}=-c_{1} z_{1}^{2} \text {. }
$$

Because (12) comprising the rotational inertia $J$ of the turbine, damping $K$ and aerodynamic torque $T_{a}$, and these quantities are as wind conditions change. For the uncertainty of these parameters, one needs to take these parameter estimates:

$$
\begin{gathered}
F=\frac{K}{J}, \\
\Gamma=\frac{T_{a}}{J} .
\end{gathered}
$$

Estimation error is defined as

$$
\begin{gathered}
\widetilde{J}=\widehat{J}-J, \\
\widetilde{F}=\widehat{F}-F, \\
\widetilde{\Gamma}=\widehat{\Gamma}-\Gamma .
\end{gathered}
$$

Equation (21) can be written as

$$
\alpha_{1}=\frac{\widehat{J}}{p \psi_{m}}\left[c_{1} z_{1}-\widehat{F}\left(z_{1}+x_{1}^{*}\right)+\widehat{\Gamma}-\dot{x}_{1}^{*}\right] .
$$

From (18), (19), and (22), we have

$$
\begin{aligned}
\dot{V}_{1}= & -c_{1} z_{1}^{2}-\frac{p \psi_{m}}{J} z_{1} z_{2}-\frac{p b_{5}}{J} x_{2} z_{1} z_{3} \\
& -\frac{\widetilde{J}}{J} z_{1}\left[c_{1} z_{1}-\widehat{F}\left(z_{1}+x_{1}^{*}\right)+\widehat{\Gamma}-\dot{x}_{1}^{*}\right] \\
& -\widetilde{F} z_{1}\left(z_{1}+x_{1}^{*}\right)-\widetilde{\Gamma} z_{1} .
\end{aligned}
$$


Step 2. Step 1 defines the stable functions $x$ and $y$, and to ensure the stability of the system, but these stable functions are ideal $d-q$ axis current. The following design of the control variables, $d-q$ axis current is able to track a desired value, to ensure the stability of the control system.

$$
\begin{aligned}
\dot{z}_{2} & =\dot{x}_{2}-\dot{\alpha}_{1} \\
& =-b_{1} \omega x_{3}-b_{2} \omega \psi_{m}-b_{3} x_{2}+b_{4} V_{q}-\dot{\alpha}_{1} .
\end{aligned}
$$

Then

$$
\begin{aligned}
& \alpha_{1}=\frac{\widehat{J}}{p \psi_{m}}\left[c_{1} z_{1}-\widehat{F}\left(z_{1}+x_{1}^{*}\right)+\widehat{\Gamma}-\dot{x}_{1}^{*}\right] \\
& \dot{\alpha}_{1}=\frac{\dot{\vec{J}}}{p \psi_{m}}\left[c_{1} z_{1}-\widehat{F}\left(z_{1}+x_{1}^{*}\right)+\widehat{\Gamma}-\dot{x}_{1}^{*}\right] \\
& +\frac{\widehat{J}}{p \psi_{m}}\left[c_{1} \dot{z}_{1}-\dot{\hat{F}} x_{1}-\widehat{F} \dot{x}_{1}+\dot{\hat{\Gamma}}-\ddot{x}_{1}^{*}\right] \\
& =\frac{\dot{\hat{J}}}{p \psi_{m}}\left[c_{1} z_{1}-\widehat{F}\left(z_{1}+x_{1}^{*}\right)+\widehat{\Gamma}-\dot{x}_{1}^{*}\right] \\
& +\frac{\widehat{J}}{p \psi_{m}}\left[-c_{1} \dot{x}_{1}^{*}-\dot{\widehat{F}} x_{1}+\dot{\widehat{\Gamma}}-\ddot{x}_{1}^{*}\right]+\frac{\widehat{J} \dot{x}_{1}}{p \psi_{m}}\left(c_{1}-\widehat{F}\right) \\
& =\frac{\dot{\hat{J}}}{p \psi_{m}}\left[c_{1} z_{1}-\widehat{F}\left(z_{1}+x_{1}^{*}\right)+\widehat{\Gamma}-\dot{x}_{1}^{*}\right] \\
& +\frac{\widehat{J}}{p \psi_{m}}\left[-c_{1} \dot{x}_{1}^{*}-\dot{\hat{F}} x_{1}+\dot{\widehat{\Gamma}}-\ddot{x}_{1}^{*}\right]+\frac{\widehat{J}}{p \psi_{m}}\left(c_{1}-\widehat{F}\right) \dot{x}_{1} \\
& =\frac{\dot{\hat{J}}}{p \psi_{m}}\left[c_{1} z_{1}-\widehat{F}\left(z_{1}+x_{1}^{*}\right)+\widehat{\Gamma}-\dot{x}_{1}^{*}\right] \\
& +\frac{\widehat{J}}{p \psi_{m}}\left[-c_{1} \dot{x}_{1}^{*}-\dot{\widehat{F}} x_{1}+\dot{\hat{\Gamma}}-\ddot{x}_{1}^{*}\right] \\
& +\frac{\widehat{J}}{p \psi_{m}}\left(c_{1}-\widehat{F}\right)\left(\frac{1}{J}\left(T_{a}-K x_{1}-p\left[\psi_{m} x_{2}+b_{5} x_{2} x_{3}\right]\right)\right) \\
& =\frac{\dot{\vec{J}}}{p \psi_{m}}\left[c_{1} z_{1}-\widehat{F}\left(z_{1}+x_{1}^{*}\right)+\widehat{\Gamma}-\dot{x}_{1}^{*}\right] \\
& +\frac{\widehat{J}}{p \psi_{m}}\left[-c_{1} \dot{x}_{1}^{*}-\dot{\hat{F}} x_{1}+\dot{\widehat{\Gamma}}-\ddot{x}_{1}^{*}\right] \\
& +\frac{\widehat{J}}{p \psi_{m}}\left(c_{1}-\widehat{F}\right)\left(\Gamma-F x_{1}\right)+\frac{\widehat{J}}{J}\left(c_{1}-\widehat{F}\right)\left(\frac{b_{5} x_{2} x_{3}}{\psi_{m}}-x_{2}\right) .
\end{aligned}
$$

From (27), (28), we have

$$
\begin{aligned}
\dot{z}_{2}= & -b_{1} \omega x_{3}-b_{2} \omega \psi_{m}-b_{3} x_{2}+b_{4} V_{q} \\
& -\frac{\widehat{J}}{p \psi_{m}}\left(c_{1}-\widehat{F}\right)\left(\Gamma-F x_{1}\right) \\
& -\frac{\widehat{J}}{J}\left(c_{1}-\widehat{F}\right)\left(\frac{b_{5} x_{2} x_{3}}{\psi_{m}}-x_{2}\right) \\
& -\frac{\dot{\hat{J}}}{p \psi_{m}}\left[c_{1} z_{1}-\widehat{F}\left(z_{1}+x_{1}^{*}\right)+\widehat{\Gamma}-\dot{x}_{1}^{*}\right] \\
& -\frac{\widehat{J}}{p \psi_{m}}\left[-c_{1} \dot{x}_{1}^{*}-\dot{\widehat{F}} x_{1}+\dot{\hat{\Gamma}}-\ddot{x}_{1}^{*}\right] .
\end{aligned}
$$

Therefore, $q$-axis control voltage can be written as

$$
\begin{aligned}
V_{q}= & \frac{b_{1} \omega x_{3}}{b_{4}}+\frac{b_{2} \omega \psi_{m}}{b_{4}}+\frac{b_{3} x_{2}}{b_{4}}+\frac{\widehat{J}}{p \psi_{m} b_{4}}\left(c_{1}-\widehat{F}\right)\left(\widehat{\Gamma}-\widehat{F} x_{1}\right) \\
& +\frac{1}{b_{4}}\left[\left(c_{1}-\widehat{F}\right)\left(\frac{b_{5} x_{2} x_{3}}{\psi_{m}}-x_{2}\right)\right] \\
& +\frac{\dot{\hat{J}}}{p \psi_{m} b_{4}}\left[c_{1} z_{1}-\widehat{F}\left(z_{1}+x_{1}^{*}\right)+\widehat{\Gamma}-\dot{x}_{1}^{*}\right] \\
& +\frac{\widehat{J}}{p \psi_{m} b_{4}}\left[-c_{1} \dot{x}_{1}^{*}-\dot{\widehat{F}} x_{1}+\dot{\hat{\Gamma}}-\ddot{x}_{1}^{*}\right]-\frac{c_{2} z_{2}}{b_{4}},
\end{aligned}
$$

where $c_{2}>0$.

Equation (29) can be written as

$$
\begin{aligned}
\dot{z}_{2}= & -c_{2} z_{2}+\frac{\widehat{J}}{p \psi_{m} b_{4}}\left(c_{1}-\widehat{F}\right)\left(\widetilde{\Gamma}-\widetilde{F} x_{1}\right) \\
& +\frac{\widetilde{J}}{J}\left(c_{1}-\widehat{F}\right)\left(\frac{b_{5} x_{2} x_{3}}{\psi_{m}}-x_{2}\right) .
\end{aligned}
$$

From (14), (16), we have

$$
\dot{z}_{3}=\dot{x}_{3}-\dot{\alpha}_{2}=-a_{1} x_{3}+a_{2} \omega x_{2}+a_{3} V_{d}
$$


Select the Lyapunov function as

$$
\begin{aligned}
V_{2}= & V_{1}+\frac{1}{2} z_{2}^{2}+\frac{1}{2} z_{3}^{2}+\frac{1}{2 \gamma_{1} J} \widetilde{J}^{2}+\frac{1}{2 \gamma_{2}} \widetilde{F}^{2}+\frac{1}{2 \gamma_{3}} \widetilde{\Gamma}^{2} \\
\dot{V}_{2}= & \dot{V}_{1}+z_{2} \dot{z}_{2}+z_{3} \dot{z}_{3}+\frac{1}{\gamma_{1} J} \tilde{\widetilde{J}}+\frac{1}{\gamma_{2}} \widetilde{F} \dot{\widetilde{F}}+\frac{1}{\gamma_{3}} \widetilde{\Gamma} \dot{\widetilde{\Gamma}} \\
= & -c_{1} z_{1}^{2}-\frac{p \psi_{m}}{J} z_{1} z_{2}-\frac{p b_{5}}{J} x_{2} z_{1} z_{3} \\
& -\frac{\tilde{J}}{J} z_{1}\left[c_{1} z_{1}-\widehat{F}\left(z_{1}+x_{1}^{*}\right)+\widehat{\Gamma}-\dot{x}_{1}^{*}\right] \\
& +z_{2}\left\{-c_{2} z_{2}+\frac{\widehat{J}}{p \psi_{m} b_{4}}\left(c_{1}-\widehat{F}\right)\left(\widetilde{\Gamma}-\widetilde{F} x_{1}\right)\right. \\
& \left.+\frac{\tilde{J}}{J}\left(c_{1}-\widehat{F}\right)\left(\frac{b_{5} x_{2} x_{3}}{\psi_{m}}-x_{2}\right)\right\}+\frac{1}{\gamma_{1} J} \widetilde{\widetilde{J} J} \\
& -\widetilde{\Gamma} z_{1}+\frac{1}{\gamma_{2}} \widetilde{F} \dot{\widetilde{F}}+\frac{1}{\gamma_{3}} \widetilde{\Gamma} \dot{\widetilde{\Gamma}} .
\end{aligned}
$$

Therefore, $d$-axis control voltage can be written as

$$
V_{d}=\frac{a_{1}}{a_{3}} x_{3}-\frac{a_{2}}{a_{3}} \omega x_{2}+\frac{p b_{5}}{J} x_{2} z_{1}-c_{3} \frac{z_{3}}{a_{3}},
$$

where $c_{2}>0$. From (34), (35), we have

$$
\begin{aligned}
\dot{V}_{2}= & -c_{1} z_{1}^{2}-c_{2} z_{2}^{2}-c_{3} z_{3}^{2}-\frac{p \psi_{m}}{J} z_{1} z_{2} \\
& -\frac{\widetilde{J}}{J} z_{1}\left[c_{1} z_{1}-\widehat{F}\left(z_{1}+x_{1}^{*}\right)+\widehat{\Gamma}-\dot{x}_{1}^{*}\right] \\
& +\frac{\widetilde{J}}{J}\left(c_{1}-\widehat{F}\right)\left\{\left(\frac{b_{5} x_{3}}{\psi_{m}}-1\right) x_{2} z_{2}+\frac{1}{\gamma_{1}} \dot{\widetilde{J}}\right\} \\
& +\widetilde{F}\left[z_{1} x_{1}-\frac{\widehat{J}}{p \psi_{m} b_{4}}\left(c_{1}-\widehat{F}\right) x_{1}+\frac{1}{\gamma_{2}} \dot{\widetilde{F}}\right] \\
& -\widetilde{\Gamma}\left[-z_{1}+\frac{\widehat{J}}{p \psi_{m} b_{4}}\left(c_{1}-\widehat{F}\right)+\frac{1}{\gamma_{3}} \dot{\widetilde{\Gamma}}\right] .
\end{aligned}
$$

The adaptive law is designed as

$$
\begin{aligned}
& \dot{\widetilde{J}}=\gamma_{1}\left\{c_{1} z_{1}^{2}-\widehat{F}\left(z_{1}+x_{1}^{*}\right)+\widehat{\Gamma}-\dot{x}_{1}^{*}\right. \\
& \left.-\left(c_{1}-\widehat{F}\right)\left(\frac{b_{5} x_{3}}{\psi_{m}}-1\right) x_{2} z_{2}\right\}, \\
& \dot{\widetilde{F}}=\gamma_{2}\left[-z_{1} x_{1}+\frac{\widehat{J}}{p \psi_{m} b_{4}}\left(c_{1}-\widehat{F}\right) x_{1}\right], \\
& \dot{\widetilde{\Gamma}}=\gamma_{3}\left[z_{1}-\frac{\widehat{J}}{p \psi_{m} b_{4}}\left(c_{1}-\widehat{F}\right)\right] .
\end{aligned}
$$

TABLE 1: NREL 5 MW baseline wind turbine model properties.

\begin{tabular}{lc}
\hline Properties & Value \\
\hline Rating power & $5 \mathrm{MW}$ \\
Rotor orientation, configuration & Upwind, 3 blades \\
Control & Variable speed, variable pitch \\
Hub height & $90 \mathrm{~m}$ \\
Rated rotor & $12 \mathrm{rpm}$ \\
Rated generator efficiency & $98 \%$ \\
Tip speed ratio & 6.5 \\
Power coefficient & 0.46 \\
Stator resistance & $150 \Omega$ \\
\hline
\end{tabular}

Using the turbine model data from [23].

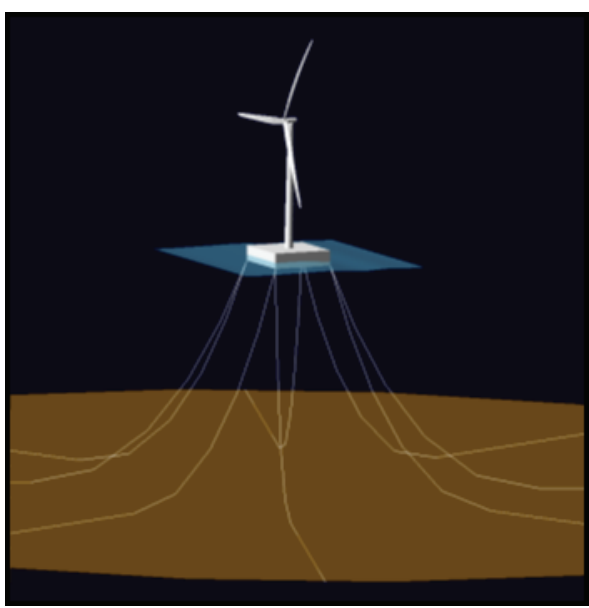

FIGURE 7: Floating wind turbine.

Therefore, we can obtain

$$
\dot{V}_{2}=-c_{1} z_{1}^{2}-c_{2} z_{2}^{2}-c_{3} z_{3}^{2}<0 .
$$

Therefore, $z_{i}(i=1,2,3) \in L_{2} \cap L_{\infty}$, and $c_{i}(i=1,2,3)>$ 0 , leading to $V_{i}(i=1,2,3) \in L_{\infty}$ and $\dot{V}_{i}(i=1,2,3) \in L_{\infty}$, Thus $z_{i}(i=1,2,3)$ is uniformly continuous, which allows Barbalat lemma to be used to conclude that $z_{i}(i=1,2,3) \rightarrow$ 0 as $t \rightarrow \infty$. By (38), the system is globally stable.

The HTSG wind turbine parameter used in the simulation is shown in Table 1.

\section{Floating Platform}

With the rapid development of offshore wind power industry, machine capacity of wind turbines is gradually increased. Due to the shallow sea area construction of wind field affect human life. The siting of wind field is established in the deep water area is a better choice. Therefore, floating offshore wind turbines generator using HTSG can reduce offshore wind farm construction and maintenance costs $[24,25]$. In this paper, the specified floating platform model used for analysis is the "NREL 5-MW baseline wind turbine mounted on a floating barge" and is shown as in Figure 7; wind turbine 


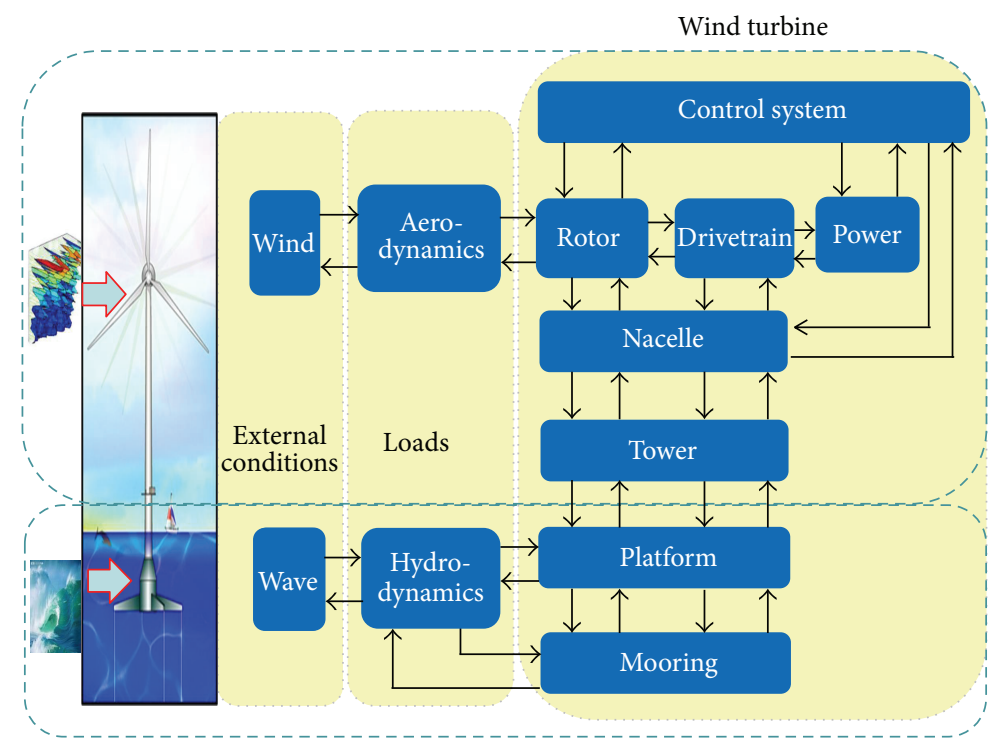

FIGURE 8: Floating offshore wind power system.

TABLE 2: NREL 5 MW baseline wind turbine model properties.

\begin{tabular}{lc}
\hline Properties & Value \\
\hline Rating power & $5 \mathrm{MW}$ \\
Rotor orientation, configuration & Upwind, 3 blades \\
Control & Variable, collective pitch \\
Drivetrain & Low speed, direct drive \\
Rotor, hub diameter & $126 \mathrm{~m}, 4 \mathrm{~m}$ \\
Hub height & $90 \mathrm{~m}$ \\
Cut-in, rated, cut-out wind speed & $3 \mathrm{~m} / \mathrm{s}, 11.4 \mathrm{~m} / \mathrm{s}, 25 \mathrm{~m} / \mathrm{s}$ \\
Cut-in, rated rotor speed & $6.9 \mathrm{rpm}, 12.1 \mathrm{rpm}$ \\
Rotor mass & $110000 \mathrm{~kg}$ \\
Nacelle mass & $24000 \mathrm{~kg}$ \\
Tower mass & $37460 \mathrm{~kg}$ \\
Coordinate Location of overall CM & $(-0.2 \mathrm{~m}, 0.0 \mathrm{~m}, 64.0)$ \\
\hline
\end{tabular}

Using the turbine model data from [23].

properties and floating platform properties are shown as in Tables 2 and 3.

Floating offshore wind energy conversion system including wind turbines, driving chain, electronic power converter, nacelle, tower, floating platform. The external environment has the wind and waves. The generality of each module also ensures that the overall simulation tool is universal enough to analyze a variety of wind turbine, support platform, and mooring system configurations. Figure 8 summarizes the modules [25].

\section{Simulation Results}

In order to evaluate the performance of the adaptive backstepping control algorithm which is proposed, the effectiveness of the proposed torque control strategy is verified through the Matlab/Simulink code (Figure 9). The wind data
TABLE 3: Physical properties of the floating platform.

\begin{tabular}{lc}
\hline Properties & Value \\
\hline Size $(W \times L \times H)$ & $40 \mathrm{~m} \times 40 \mathrm{~m} \times 10 \mathrm{~m}$ \\
Moon pool $(W \times L \times H)$ & $10 \mathrm{~m} \times 10 \mathrm{~m} \times 10 \mathrm{~m}$ \\
Draft, freeboard & $4 \mathrm{~m}, 6 \mathrm{~m}$ \\
Water displacement & $6,000 \mathrm{~m}^{3}$ \\
Mass, including ballast & $5452000 \mathrm{~kg}$ \\
CM location below SWL & $0.281768 \mathrm{~m}$ \\
Roll inertia about CM & $726900000 \mathrm{~kg} \cdot \mathrm{m}^{2}$ \\
Pitch inertia about CM & $726900000 \mathrm{~kg} \cdot \mathrm{m}^{2}$ \\
Yaw inertia about CM & $1453900000 \mathrm{~kg} \cdot \mathrm{m}^{2}$ \\
Anchor (water) depth & $150 \mathrm{~m}$ \\
Separation between opposing anchors & $773.8 \mathrm{~m}$ \\
Unstretched line length & $473.3 \mathrm{~m}$ \\
Neutral line length resting on seabed & $250 \mathrm{~m}$ \\
Line diameter & $0.0809 \mathrm{~m}$ \\
Line mass density & $130.4 \mathrm{~kg} / \mathrm{m}$ \\
Line extensional stiffness & $589000000 \mathrm{~N}$ \\
\hline
\end{tabular}

Using the turbine model data from [23].

uses the data that NREL Turbsim generates [26, 27]. In order to assess MPPT, the simulation used a turbulent wind and the obtained used Kai-mal spectrum in the IEC standard.

Verify that the paper design control algorithms, the wind and sea conditions offshore wind turbine is shown in Figures 10 and 11. As clearly shown in Figures 11, 12, and 13, Good HTSG tracking performances are achieved in wind disturbance and wave disturbance. Scanning the simulation results, it can be concluded that MPPT control is satisfactory.

The simulation results of the advanced MPPT controller with adaptive backstepping control method are demonstrated in Figures 12 and 13 compared with the same performance of the conventional PID (proportion integration differentiation) 


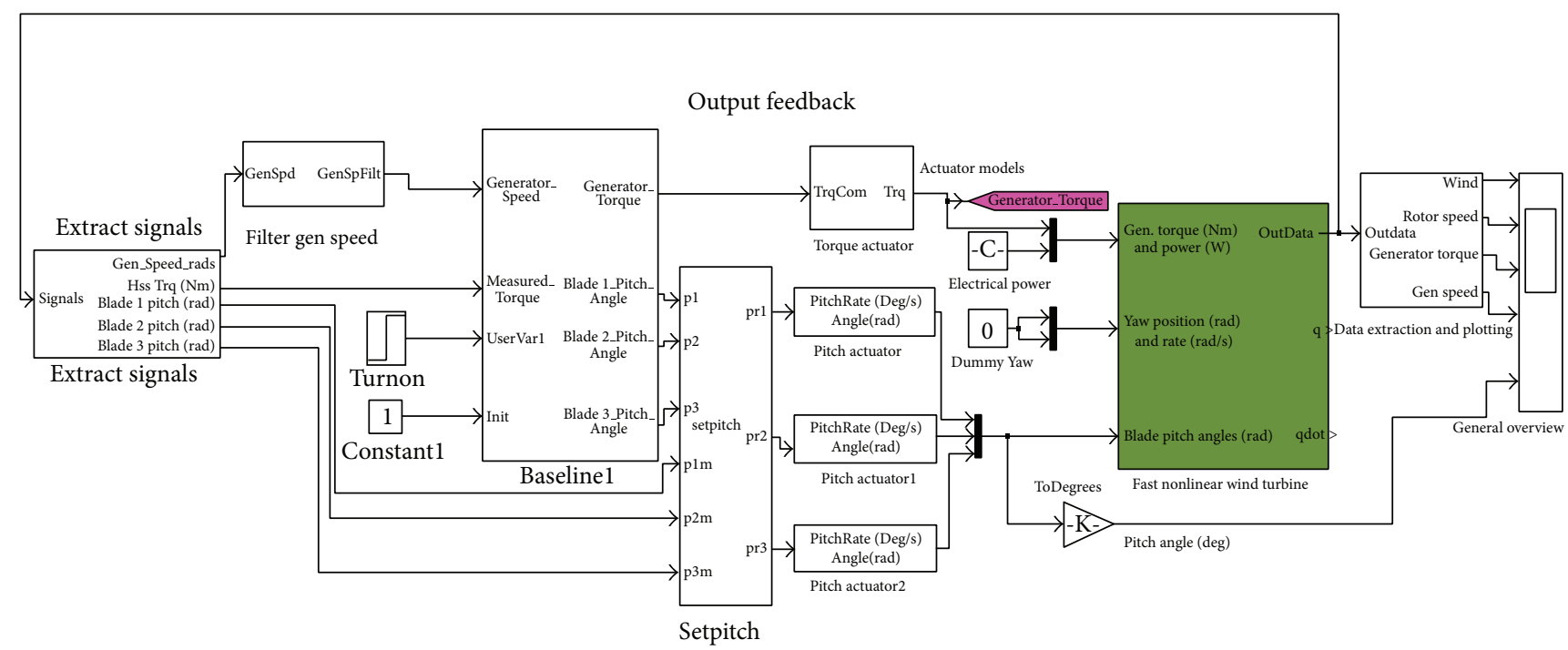

FIGURE 9: Block diagram of WECS in Matlab.

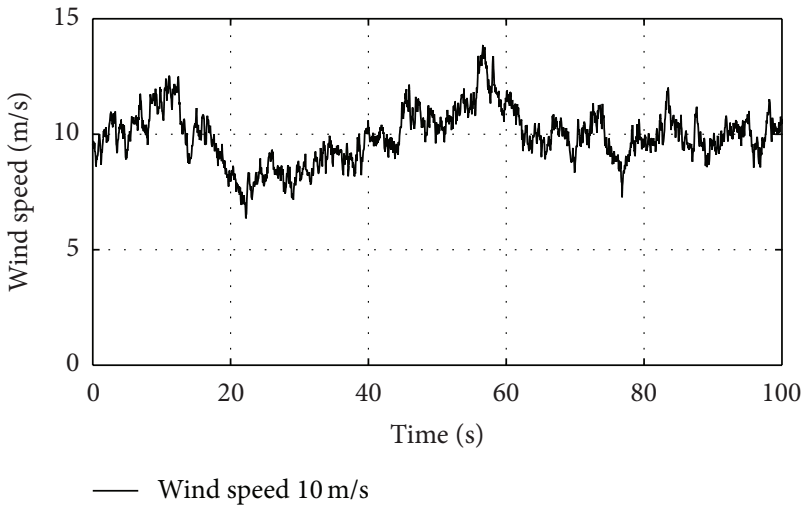

Figure 10: Wind speed.

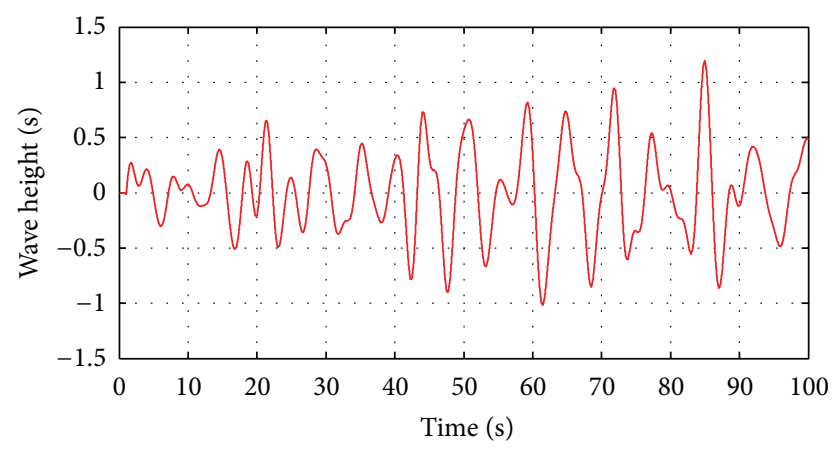

- Wave height

FIGURE 11: Wave height.

control on the basis of MPPT. Certainly contributing to the MPPT, our optimized algorithm has effectively conducted the experiment.

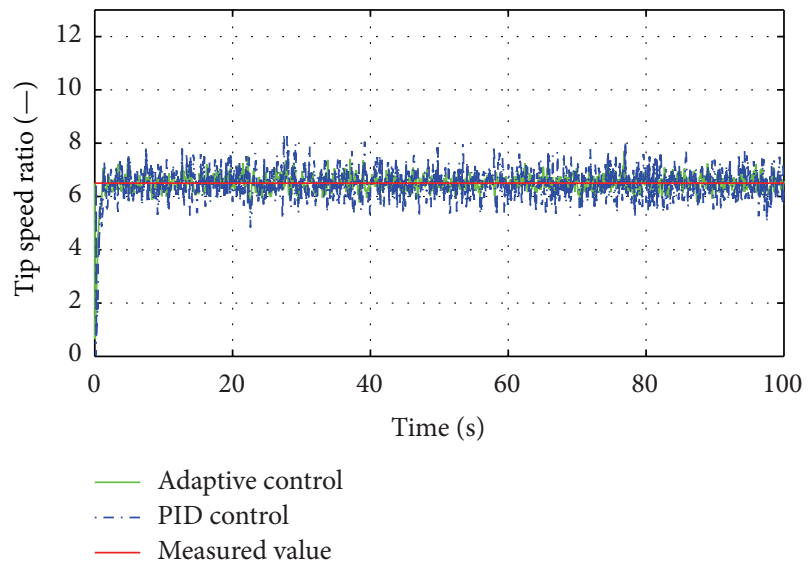

FIGURE 12: Comparison of tip speed ratio tracking.

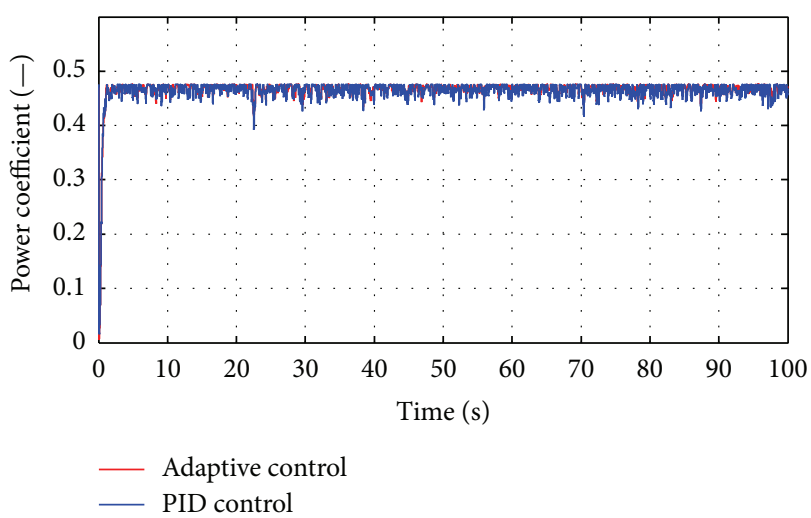

Figure 13: Power coefficient.

\section{Conclusion}

The author presented two kinds of generators that can be used to convert wind energy into electric energy. Power capacity 
and weight are limited in traditional technology which is used in wind applications. With the increasing of the wind power generation unit capacity, superconducting technology is a good choice for wind turbines. Superconducting technology is relatively mature to develop the wind turbines of high efficiency and power density compare with DFIG or PMSG.

A model-independent control scheme based on adaptive backstepping control method has been developed for torque tracking of HTSG system. We establish torque and flux tracking of proposed adaptive backstepping control scheme according to Lyapunov stability theory. Adaptive backstepping control algorithm is put forward for its prominent features such as the robustness of parameter disturbance in the turbines and the electric grid disturbance. Numerical analysis and simulation results clearly show that the adaptive backstepping control method is more effective than the traditional methods in terms of MPPT.

\section{Conflict of Interests}

The authors declare that there is no conflict of interests regarding the publication of this paper.

\section{Acknowledgments}

This work was supported in part by the National High Technology Research and Development Program of China (SS2012AA052302), Fundamental Research Funds for the Central Universities (ZYGX2012J093), and National Natural Science Foundation of China (51205046).

\section{References}

[1] A. Thomas, Wind Power in Power Systems, vol. 1, John Wiley \& Sons, West Sussex, UK, 2005.

[2] World Wind Energy Association, "World wind energy installed capacity," 2013, http://www.wwindea.org/.

[3] A. B. Abrahamsen, N. Mijatovic, E. Seiler et al., "Superconducting wind turbine generators," Superconductor Science and Technology, vol. 23, no. 3, Article ID 034019, pp. 3-10, 2010.

[4] A. B. Abrahamsen, N. Mijatovic, E. Seiler et al., "Design study of $10 \mathrm{~kW}$ superconducting generator for wind turbine applications," IEEE Transactions on Applied Superconductivity, vol. 19, no. 3, pp. 1678-1682, 2009.

[5] A. Petersson, L. Harnefors, and T. Thiringer, "Evaluation of current control methods for wind turbines using doubly-fed induction machines," IEEE Transactions on Power Electronics, vol. 20, no. 1, pp. 227-235, 2005.

[6] G. Ramtharan, J. B. Ekanayake, and N. Jenkins, "Frequency support from doubly fed induction generator wind turbines," IET Renewable Power Generation, vol. 1, no. 1, pp. 3-9, 2007.

[7] C. Wenping, "High-temperature superconducting wind turbine generators," in Wind Turbines, I. Al-Bahadly, Ed., InTech, Rijeka, Croatia, 2011.

[8] L. Shuhui, T. A. Haskew, R. P. Swatloski, and W. Gathings, "Optimal and direct-current vector control of direct-driven PMSG wind turbines," IEEE Transactions on Power Electronics, vol. 27, no. 5, pp. 2335-2337, 2012.

[9] Z. Zhang, T. King-Jet, D. M. Vilathgamuwa, T. D. Nguyen, and X.-Y. Wang, "Design of a robust grid interface system for
PMSG-based wind turbine generators," IEEE Transactions on Industrial Electronics, vol. 58, no. 1, pp. 316-328, 2011.

[10] S. Bacha, J. Guiraud, I. Munteanu, A. Bratcu, and D. Roye, "Energy-reliability optimization of wind energy conversion systems by sliding mode control," IEEE Transactions on Energy Conversion, vol. 23, no. 3, pp. 975-985, 2008.

[11] S. M. Muyeen, Wind Energy Conversion Systems: Technology and Trends, Springer, London, UK, 2012.

[12] N. Mijatovic, B. B. Jensen, C. Træholt et al., "High temperature superconductor machine prototype," in Proceedings of the International Conference on Electrical Machines and Systems (ICEMS '11), pp. 1-6, Beijing, China, August 2011.

[13] M. R. Quddes, M. Sekino, and H. Ohsaki, "Electromagnetic design study of $10 \mathrm{MW}$-class wind turbine generators using circular superconducting field coils," in Proceedings of the International Conference on Electrical Machines and Systems (ICEMS '11), pp. 1-6, Beijing, China, August 2011.

[14] J. M. Fogarty, "Development of a 100 MVA high temperature superconducting generator," in Proceedings of the IEEE Power Engineering Society General Meeting, vol. 2, pp. 2065-2067, Denver, Colo, USA, June 2004.

[15] D. R. Rush and G. W. David, Nonlinear Power Flow Control Design, Springer, New York, NY, USA, 2011.

[16] S. S. Kalsi, K. Weeber, H. Takesue, C. Lewis, H.-W. Neumueller, and R. D. Blaugher, "Development status of rotating machines employing superconducting field windings," Proceedings of the IEEE, vol. 92, no. 10, pp. 1688-1704, 2004.

[17] H. Ohsaki, M. Sekino, T. Suzuki, and Y. Terao, "Design study of wind turbine generators using superconducting coils and bulks," in Proceedings of the International Conference on Clean Electrical Power (ICCEP '09), pp. 479-484, Capri, Italy, June 2009.

[18] H. Ohsaki, M. Sekino, T. Suzuki, and Y. Terao, "Design study of wind turbine generators using superconducting coils and bulks," in Proceedings of the International Conference on Clean Electrical Power (ICCEP '09), pp. 479-484, Capri, Italy, June 2009.

[19] S. E. Ben, M. El Hachemi Benbouzid, T. Ahmed-Ali, and J. F. Charpentier, "High-order sliding mode control of a marine current turbine driven doubly-fed induction generator," IEEE Journal of Oceanic Engineering, vol. 35, no. 2, pp. 402-411, 2010.

[20] L. Hui, C. Zhe, and H. Polinder, "Optimization of multibrid permanent-magnet wind generator systems," IEEE Transactions on Energy Conversion, vol. 24, no. 1, pp. 82-92, 2009.

[21] C. S. Yong, Superconducting Motor, ZheJiang University Press, Zhengjiang, China, 1992.

[22] J. D. Phillip, "Wind turbine control design to reduce capital costs," Tech. Rep. NREL/SR-500-46442, National Renewable Energy Laboratory, Golden, Colo, USA, 2010.

[23] J. Jonkman and S. Butterfield, "Definition of a 5-MW reference wind turbine for offshore system development," Tech. Rep. NREL/TP-500-29415, National Renewable Energy Laboratory, Golden, Colo, USA, 2002.

[24] L. Wang, B. Wang, Y. D. Song et al., "Fatigue loads alleviation of floating offshore wind turbine using individual pitch control," Advances in Vibration Engineering, vol. 12, no. 4, pp. 377-390, 2013.

[25] S. Zuo, Y. D. Song, L. Wang, and Q.-W. Song, "Computationally inexpensive approach for pitch control of offshore wind turbine on barge floating platform," The Scientific World Journal, vol. 2013, Article ID 357849, 9 pages, 2013. 
[26] J. Jonkman, “TurbSim user's guide: version 1.50,” Tech. Rep. NREL/TP-500-46198, National Renewable Energy Laboratory, Golden, Colo, USA, 2009.

[27] N. D. Kelly and J. Jonkman, "Overview of the TurbSim stochastic inflow turbulence simulator," Tech. Rep. NREL/TP-50041137, National Renewable Energy Laboratory, Golden, Colo, USA, 2007. 


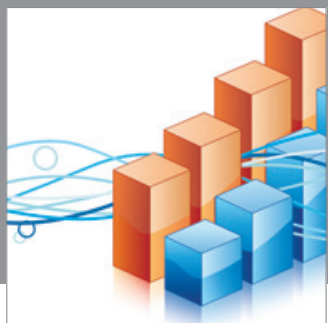

Advances in

Operations Research

mansans

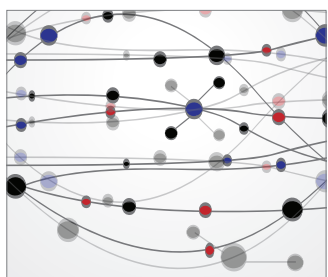

The Scientific World Journal
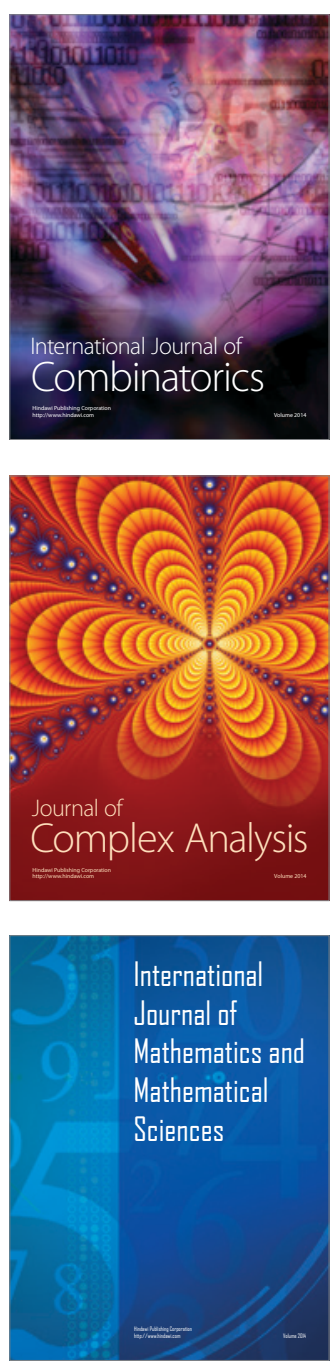
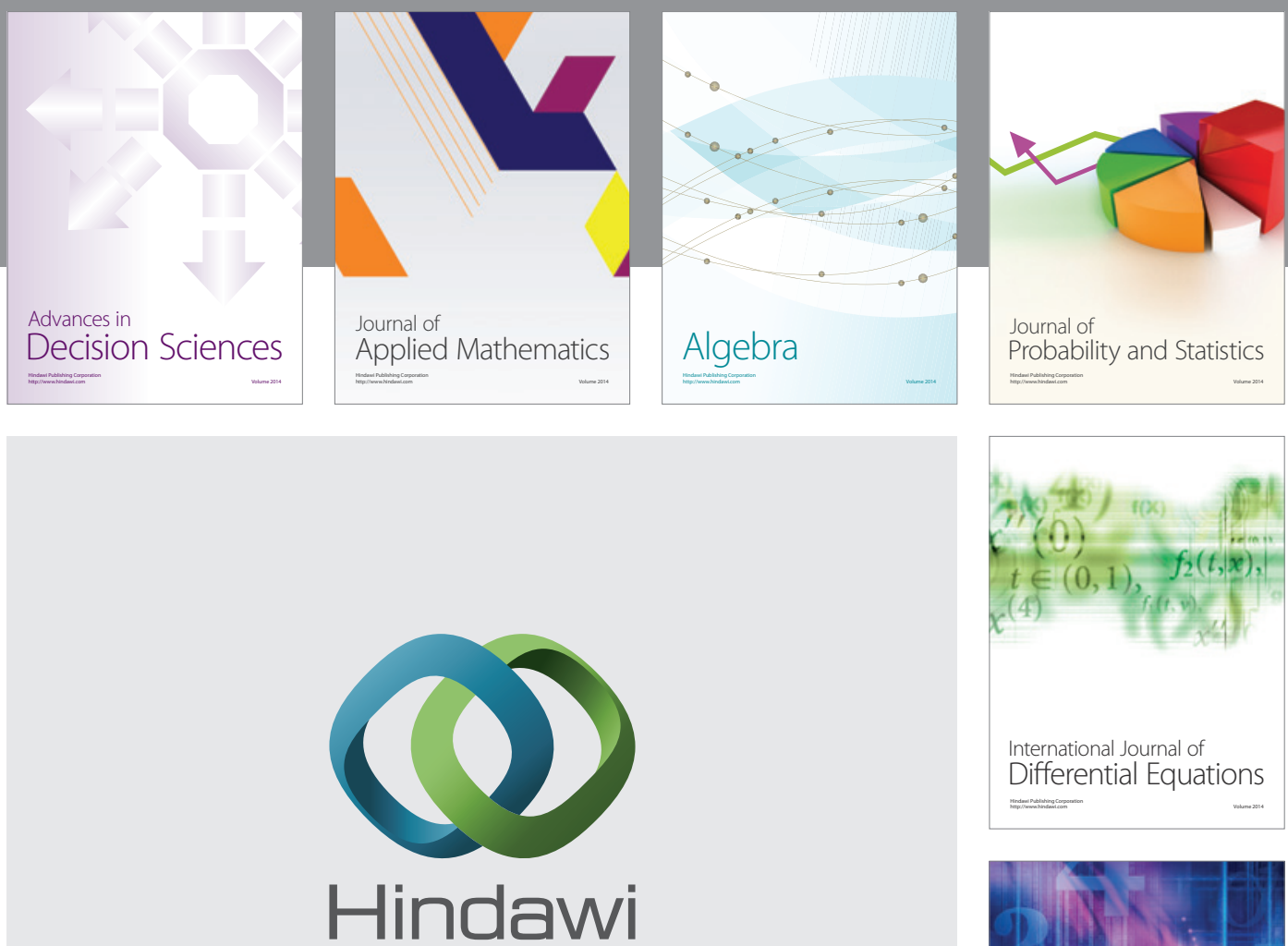

Submit your manuscripts at http://www.hindawi.com
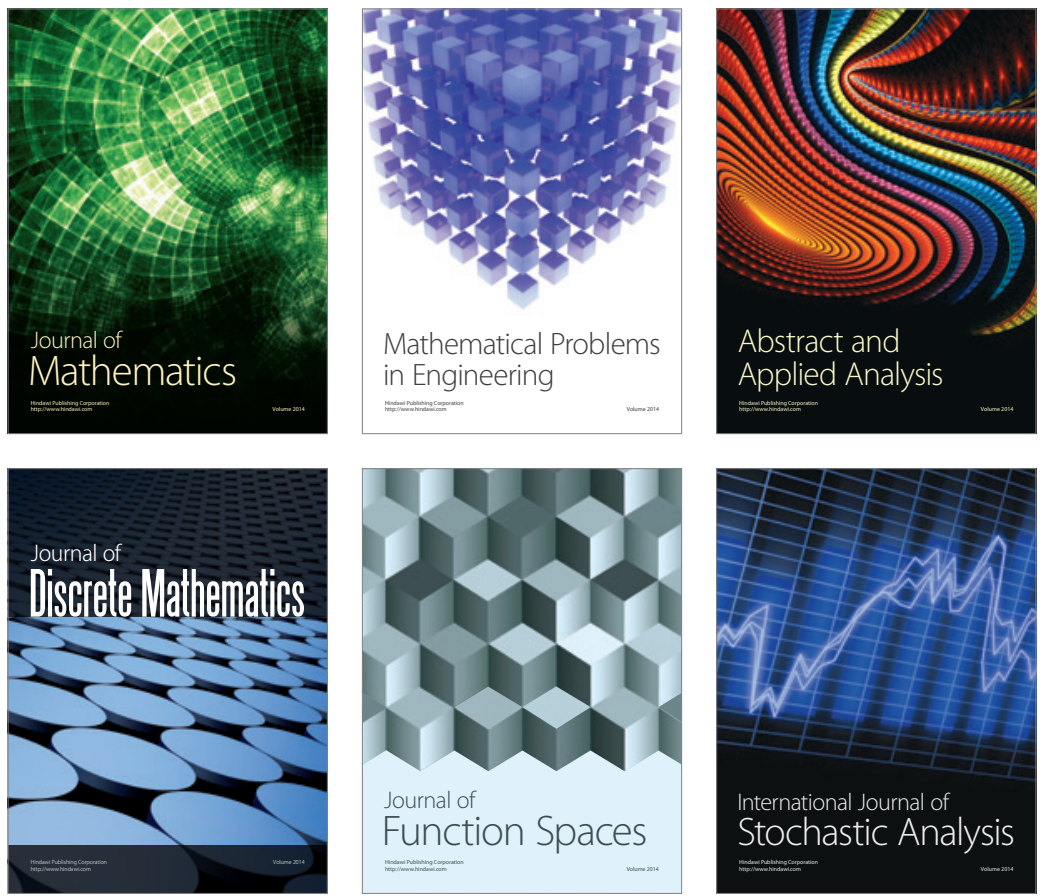

Journal of

Function Spaces

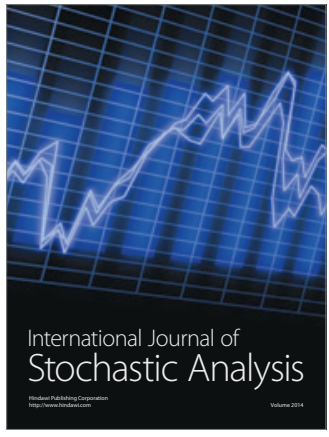

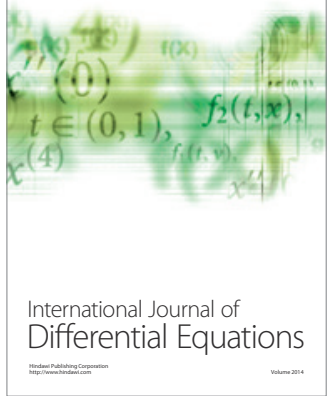
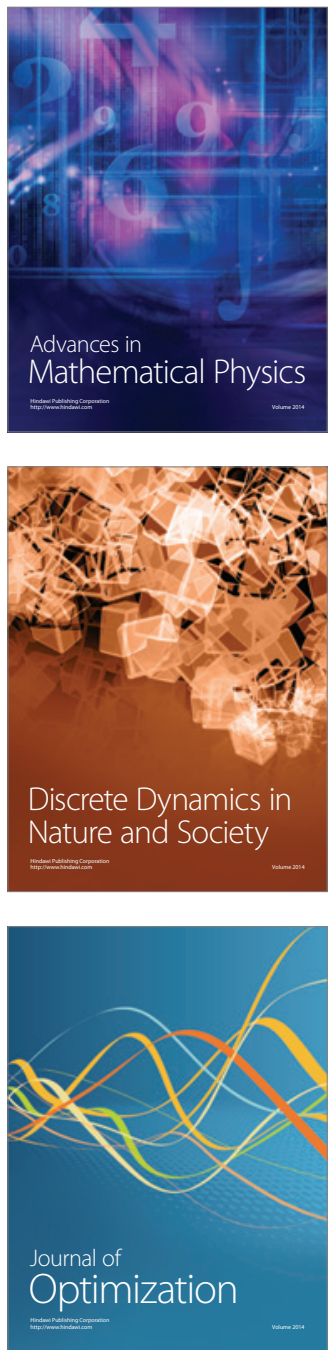